\title{
Case Report \\ Death from Liver Failure despite Lamivudine Prophylaxis during R-CHOP Chemotherapy due to Rapid Emergence M204 Mutations
}

\author{
Lay Lay Win, ${ }^{1}$ Jeff Powis, ${ }^{2}$ Hemant Shah,, ${ }^{1}$ Jordan J. Feld, ${ }^{1}$ and David K. Wong' \\ ${ }^{1}$ Hepatology, Toronto Western Hospital, University of Toronto, 399 Bathurst Street, 6b-176, Toronto, ON, Canada M5T 2 S8 \\ ${ }^{2}$ Infectious Diseases, Toronto East General Hospital, 825 Coxwell Avenue, East York, ON, Canada M4C 3E7 \\ Correspondence should be addressed to Lay Lay Win; laylay.win@gmail.com
}

Received 23 June 2013; Accepted 8 July 2013

Academic Editors: N. Koike, H. Nagahara, and N. Snyder

Copyright @ 2013 Lay Lay Win et al. This is an open access article distributed under the Creative Commons Attribution License, which permits unrestricted use, distribution, and reproduction in any medium, provided the original work is properly cited.

\begin{abstract}
Background. Rapid and early emergence of clinically significant LAM resistance is thought to be unlikely during the first year of treatment, and as a result LAM is thought to be a reasonable choice as a first line agent for prophylaxis during chemotherapy. Aim. To report fatal HBV reactivation despite appropriate LAM prophylaxis in two previously treatment-naive individuals undergoing R-CHOP chemotherapy. Case Presentation. Case 1 is a 65-year-old man with chronic HBV infection: HBeAg-negative, HBV DNA $6.65 \mathrm{E} 5 \mathrm{IU} / \mathrm{mL}$, ALT $43 \mathrm{IU} / \mathrm{L}$, and Fibroscan $4.4 \mathrm{kPa}$, consistent with F0, who was diagnosed with lymphoma that was treated with RCHOP and LAM prophylaxis. HBV DNA fell to $2.18 \mathrm{E} 1 \mathrm{IU} / \mathrm{mL}$ within 2 months of starting LAM. Four months after chemotherapy, despite ongoing LAM of 7-month duration with confirmed adherence, severe asymptomatic hepatitis was noted during routine monitoring with ALT $1019 \mathrm{IU} / \mathrm{L}, \mathrm{HBeAg}$ negative, HBV DNA 1.43E7 IU/mL, and genotyping confirmed L80I and M204I mutations. He died 14 days after flare diagnosis despite a switch to tenofovir (HBV DNA had fallen to 1.94E5 IU/mL 2 weeks after starting tenofovir). Case 2 is a 50-year-old man who was found to have HBeAg-negative hepatitis B, ALT 37 IU/L, and no clinical features of cirrhosis (platelets 283, APRI 0.19) after lymphoma diagnosis. Lymphoma was treated with R-CHOP and LAM prophylaxis. Pretreatment HBV DNA was not done but was $8.90 \mathrm{E} 4 \mathrm{IU} / \mathrm{mL} 3$ weeks after starting LAM and 3.96E3 IU/mL $3 \mathrm{months}$ after starting LAM. Two months after chemotherapy, despite ongoing LAM of 7-month duration with confirmed adherence, severe symptomatic hepatitis presenting with jaundice, abdominal pain, and confusion was noted. ALT 902 IU/L, HBeAg negative, HBV DNA 1.02E8 IU/mL, and genotyping confirmed L80I, M80V, and M204V/S mutations. He died 3 days after flare diagnosis despite the addition of tenofovir. Conclusion. Lamivudine should not be used for prophylaxis of patients with chronic hepatitis B with detectable HBV DNA undergoing chemotherapy with rituximab containing cytotoxic chemotherapy even if they have never had exposure to lamivudine in the past. In this setting, lamivudine failure due to resistance can develop quickly leading to liver failure that cannot be salvaged with tenofovir. Whether LAM is safe for prophylaxis with rituximab-based cytotoxic chemotherapy for patients with undetectable HBV DNA is unknown, but agents with a high barrier to resistance may be preferable.
\end{abstract}

\section{Introduction}

Reactivation of hepatitis B infection has been reported in $20 \%-50 \%$ of patients during conventional chemotherapy and up to $80 \%$ of patients during rituximab-containing chemotherapy [1]. Chemotherapy-induced reactivation occurs in not only hepatitis B surface antigen- (HBsAg-) positive patients but also in HBsAg-negative/anti-hepatitis $\mathrm{B}$ core antibody- (anti-HBc-) positive patients, particularly when rituximab is used [2]. Reactivation is thought to reflect a loss of immune control resulting in abrupt increase in viral replication with or without ALT flare that can be asymptomatic or lead to jaundice in $26 \%$, nonfatal liver failure in $3.7 \%$, and even death in $7 \%$ of those with positive HBsAg [3].

The Centers for Disease Control and Prevention (CDC) recommends testing for $\mathrm{HBsAg}$, anti-HBc, and anti-hepatitis B surface $\mathrm{Ab}$ (anti-HBs) in persons needing immunosuppressive therapy, including cancer chemotherapy, immunosuppression related to organ transplantation, 
and immunosuppression for rheumatological, dermatological, or gastroenterological disorders [4].

Many studies have shown the effectiveness of lamivudine to prevent chemotherapy-associated hepatitis B reactivation, with 2 meta-analyses showing a survival benefit to this approach $[5,6]$. Katz et al. performed a systematic review and meta-analysis of the effectiveness of lamivudine for all chemoprophylaxis including rituximab-based chemotherapy and found a marked reduction in both clinical and virological reactivations compared to no treatment (OR 0.09; 95\% confidence interval (CI) $0.05-0.14$ and OR 0.04 ; $95 \%$ CI $0.01-$ 0.20 , resp.). All-cause mortality was significantly reduced in the patients who received lamivudine (OR 0.39; $95 \%$ CI 0.24-0.62), and prophylaxis also reduced HBV-related mortality (OR 0.20; 95\% CI 0.09-0.45) and discontinuation or disruptions of the immunosuppressive treatment [5]. Loomba et al. showed a similar finding that the relative risk for both $\mathrm{HBV}$ reactivation and $\mathrm{HBV}$-related hepatitis ranged from 0.00 to 0.21 with preventive lamivudine and none of the patients in the preventive lamivudine group developed HBVrelated hepatic failure [6].

The American Association for the Study of Liver Diseases (AASLD) guidelines recommend prophylactic antiviral therapy for HBsAg-positive patients at the onset of immunosuppressive treatment and to continue for 6 months afterwards [7]. Clear guidelines on how to manage patients who are $\mathrm{HBsAg}$ negative/anti-HBc positive are lacking, but monitoring is required and it is recommended to start antiviral therapy if HBV DNA becomes detectable (AASLD guidelines Hepatology 2008).

Currently, lamivudine is still used as the first line antiviral agent for prophylaxis to prevent hepatitis $\mathrm{B}$ reactivation during immunosuppressive therapy, as it is cheap, safe, and well tolerated. However, the long-term efficacy of lamivudine is limited by the frequent emergence of lamivudine-resistant hepatitis $B$ virus [8]. The incidence of resistance has been reported to be approximately $20 \%$ annually in immunocompetent patients receiving long-term treatment [9]. Pelizzari et al. analysed 32 cases of primary lamivudine prophylaxis given to HBV carriers with hematologic malignancies for median followup of 19.5 months and found that the HBV YMMD mutant occurred in only $3.1 \%$ of patients with no clinical relevance [10]. Rapid and early emergence of clinically significant resistance is thought to be unlikely during the first year of treatment, particularly for patients with low HBV DNA levels at baseline, and as a result, lamivudine is thought to be a reasonable choice as prophylaxis for most patients during chemotherapy, particularly those scheduled to require prophylaxis for less than one year (AASLD guidelines). This premise is challenged by our recent experience where fatal HBV reactivation was observed despite appropriate lamivudine prophylaxis in two previously treatment-naive individuals undergoing R-CHOP chemotherapy.

\section{Case Report}

2.1. Case 1. A 65-year-old Chinese man was diagnosed with stage IIA diffuse, large B-cell lymphoma in April 2011 after

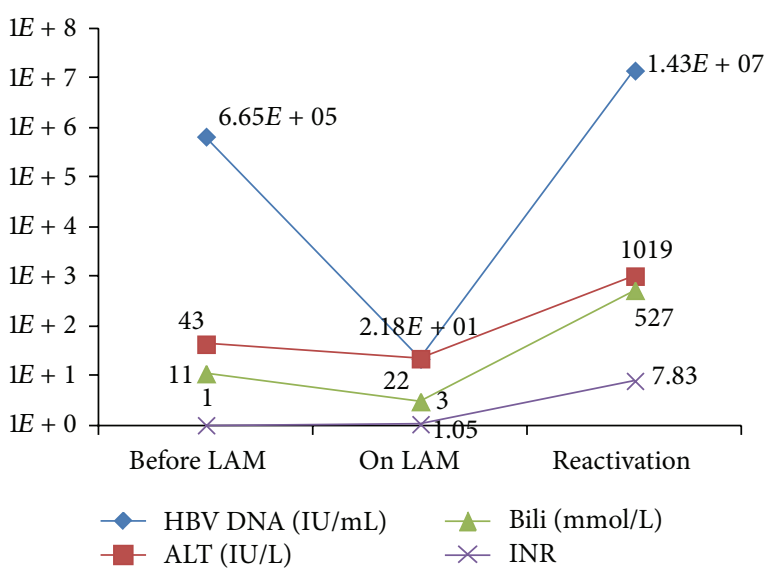

FIgURE 1: : Biochemical and HBV DNA VL changes in Case 1.

presenting with cervical lymphadenopathy. His past medical history was significant for hypertension, thyroidectomy in 2008 for papillary cancer, thalassemia trait, and right inguinal hernia. He was known to have chronic HBV infection but had been told he was an "inactive carrier" and did not receive regular followup and had never received antiviral therapy. He was taking levothyroxine $0.112 \mathrm{mg}$, valsartan $160 \mathrm{mg}$, and hydrochlorothiazide $12.5 \mathrm{mg}$ daily. He was also found to have latent TB during screening before R-CHOP chemotherapy. $\mathrm{He}$ received the first cycle of R-CHOP on June 2, 2011. He was evaluated by the hepatology service the same week, and lamivudine $100 \mathrm{mg}$ daily was started immediately, on June 10, 2011. Isoniazid $300 \mathrm{mg}$ daily and pyridoxine $25 \mathrm{mg}$ daily were started for latent TB on July 24, 2011, at the recommendation of the infectious disease consultant. Chemotherapy was complicated by febrile neutropenia after the second cycle of R-CHOP, treated with piperacillin-tazobactam (Tazocin) and filgrastim (neupogen), and he subsequently received levofloxacin prophylaxis for the fifth and sixth cycles of chemotherapy. Metformin was also started after the fifth cycle for hyperglycemia. He finished a total of 6 cycles of R-CHOP on September 16, 2011.

Evaluation of the hepatitis B status prechemotherapy showed that he was $\mathrm{HBeAg}$ negative and anti-HBe positive with an HBV DNA of $6.65 \mathrm{E} 5 \mathrm{IU} / \mathrm{mL}$ and ALT of $43 \mathrm{IU} / \mathrm{L}$. Fibroscan was $4.4 \mathrm{KPa}$, suggesting F0 (no) liver fibrosis. There was a good initial response to lamivudine, as HBV DNA fell to $2.18 \mathrm{E} 1 \mathrm{IU} / \mathrm{mL}$ after 2 months of therapy. His ALT was $36 \mathrm{IU} / \mathrm{L}$ after two months, $22 \mathrm{IU} / \mathrm{L}$ after three months, and $23 \mathrm{IU} / \mathrm{L}$ after 4 months (October 2011) of treatment.

On January 18, 2012, ALT was found to be increased to $79 \mathrm{IU} / \mathrm{L}$ on routine bloodwork. Repeated bloodwork on February 2, 2012, 4 months after completing chemotherapy, showed ALT $877 \mathrm{IU} / \mathrm{L}$, AST $1188 \mathrm{IU} / \mathrm{L}$, ALP $118 \mathrm{IU} / \mathrm{L}$, total bilirubin $226 \mathrm{mmol} / \mathrm{L}$, INR 3.21, and HBV DNA $1.34 \mathrm{E} 7 \mathrm{IU} / \mathrm{mL}$ (Figure 1). The patient was notably jaundiced but otherwise asymptomatic. He and his family confirmed adherence to lamivudine during and after completing chemotherapy. He was admitted to hospital, despite feeling well, and ALT peaked at ALT $1019 \mathrm{IU} / \mathrm{L}$. INH was also 
discontinued; however the marked rise in HBV DNA was strongly suggestive of HBV-reactivation-associated hepatitis rather than INH hepatotoxicity. HBeAg remained negative, and genotyping with the INNO-LIPA assay confirmed L80I and M204I mutations, conferring lamivudine resistance. Tenofovir was started on presentation; however there was continued deterioration with investigations showing ALT $578 \mathrm{IU} / \mathrm{L}$, AST $619 \mathrm{IU} / \mathrm{L}$, ALP $121 \mathrm{IU} / \mathrm{L}$, total bilirubin $534 \mathrm{mmol} / \mathrm{L}$, INR 7.05, and HBV DNA 1.94E5 IU/mL. With the continued deterioration despite potent antiviral therapy, a decision was made to add prednisone therapy for a possible anti-inflammatory effect with continuation of tenofovir. Unfortunately there was no clinical response to prednisone, and the patient died on February 17, 2012, from progressive liver failure.

2.2. Case 2. A 50-year-old Canadian man of Chinese ancestry was diagnosed with stage III diffuse and large B-cell lymphoma in June 2011 after presenting with cervical lymphadenopathy. His past medical history was significant for gout and psoriasis for which he was using betamethasone/calcipotriol ointment (Dovobet) topically. Hepatitis $\mathrm{B}$ was diagnosed during screening for chemotherapy. $\mathrm{He}$ received the first cycle of R-CHOP on August 18, 2011, and lamivudine $100 \mathrm{mg}$ daily was started on August 22, 2011. After the first cycle of R-CHOP chemotherapy, he had a significant ALT flare and the second cycle was postponed for 2 weeks with a subsequent $50 \%$ dose reduction during the second and third cycles of chemotherapy. He received full dose of chemotherapy after the third cycle. He finished 6 cycles of RCHOP in February 2012.

Evaluation of the hepatitis B status prechemotherapy showed that he was HBeAg negative. Unfortunately, HBV DNA was not tested, but ALT was $37 \mathrm{IU} / \mathrm{L}$. He did not have clinical evidence of advanced liver fibrosis (platelets $283 \times 10 \mathrm{E} 9 / \mathrm{mL}$, AST $21 \mathrm{IU} / \mathrm{L}$, APRI 0.19, suggesting F0 (no) liver fibrosis). After the first cycle of R-CHOP, 24 days after starting lamivudine, his ALT went up to $440 \mathrm{IU} / \mathrm{L}$ and AST to $115 \mathrm{IU} / \mathrm{L}$. With the ALT flare, the HBV DNA was measured and found to be $8.90 \mathrm{E} 4 \mathrm{IU} / \mathrm{mL}$. He continued on lamivudine. His ALT subsequently normalized and remained normal during the next 5 cycles of chemotherapy. The HBV DNA was repeated in mid-October 2011 and had declined to $3.96 \mathrm{E} 3 \mathrm{IU} / \mathrm{mL}$, indicating at least a $1.4 \log$ drop with 2 months of lamivudine therapy. The ALT was normal on subsequent testing in January $2012(30 \mathrm{IU} / \mathrm{L})$ and was found to be slightly elevated at $43 \mathrm{IU} / \mathrm{L}$ on March 19, 2012.

At the end of March 2012, he became unwell with fatigue, nausea, and vomiting. On April 10, 2012, two months after completing chemotherapy, while still on lamivudine, he became jaundiced and was admitted to the hospital with acute liver failure. At the time of admission, he had been taking lamivudine for a total of 7 months with confirmed adherence. Investigations revealed a peak ALT of $902 \mathrm{IU} / \mathrm{L}$, AST $612 \mathrm{IU} / \mathrm{L}$, total bilirubin $249 \mathrm{mmol} / \mathrm{L}$, INR 7.3 (Figure 2). HBeAg status was not done, but HBV DNA was found to have risen to $1.02 \mathrm{E} 8 \mathrm{IU} / \mathrm{mL}$. Genotyping with the INNOLIPA assay confirmed L80I, M80V, and M204V/S mutations,

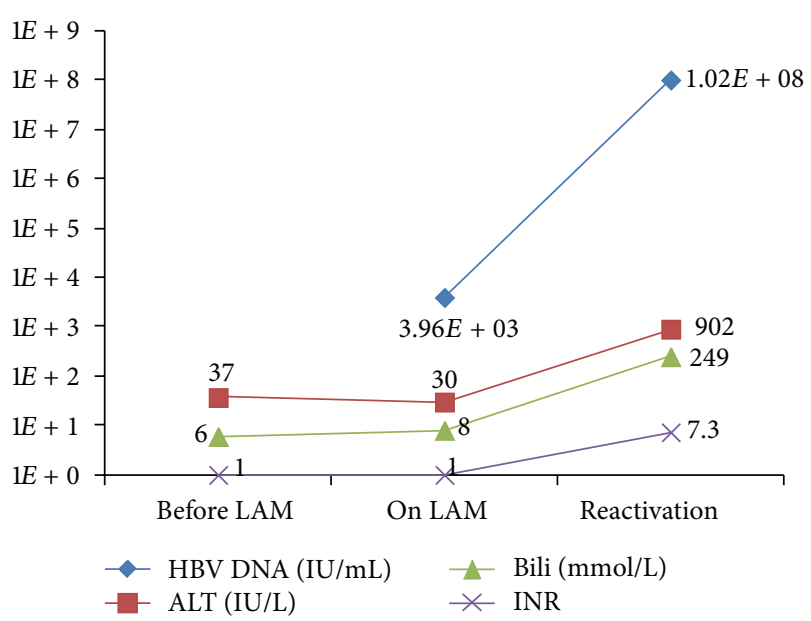

FIgURE 2: Biochemical and HBV DNA VL changes in Case 2.

conferring lamivudine resistance. Despite immediate addition of tenofovir, the patient died 3 days later.

\section{Discussion}

Hepatitis $B$ reactivation due to chemotherapy is thought to occur from loss of HBV immune control allowing high-level HBV replication in hepatocytes. The subsequent immune reconstitution after chemotherapy can result in a severe inflammatory syndrome resulting in massive destruction of infected hepatocytes, hepatitis, and liver failure. Loss of HBVspecific immunity seems more likely if rituximab or steroid therapy is combined with standard cytotoxic chemotherapy [11, 12]. Rituximab is a monoclonal anti-CD20 antibody that causes long-lasting B-cell depletion that may last as long as 3 years after stopping the medication [13]. Why rituximab specifically leads to more frequent and potentially more severe HBV-reactivation is unknown but suggests the importance of B cells in HBV immune control.

The two cases presented were very similar (Table 1). Both patients had relatively inactive HBV infection with detectable HBV DNA but normal ALT and no evidence of advanced liver fibrosis. Importantly both patients were treatment-naïve. Both patients reported adherence with medication but neither adhered perfectly to the required monitoring for lamivudine therapy. HBV DNA monitoring is recommended every 3 months during lamivudine treatment. However patient 1 missed his November 2011 visit, which may have identified the presence of genotypic resistance before he presented with clinical liver failure 2 months later. Patient 2 did not have HBV DNA viral load before starting chemotherapy, he missed his March 2012 visit, and he presented with clinical symptoms 1 month later. As has been previously well described, both patients presented with HBV reactivation after completing chemotherapy, presumably due to immune reconstitution leading to hepatitis. Despite taking lamivudine for only 7 months with relatively low viral loads at baseline, both patients developed mutations conferring 
TABLE 1: Basic characteristics and summary of cases.

\begin{tabular}{|c|c|c|}
\hline Characteristics & Case 1 & Case 2 \\
\hline Age (years) & 65 & 50 \\
\hline Sex & Male & Male \\
\hline Ethnicity & Chinese & Chinese \\
\hline HBV status before chemotherapy & $\begin{array}{l}\text { HBeAg negative, } \\
\text { Anti-HBe positive, HBV DNA } \\
6.65 \mathrm{E} 5 \mathrm{IU} / \mathrm{mL}, \text { ALT } 43 \mathrm{IU} / \mathrm{L}\end{array}$ & $\begin{array}{l}\text { HBeAg negative, } \\
\text { Anti-HBe positive, HBV DNA } \\
\text { 8.90E4 IU/mL*, ALT } 37 \text { IU/L }\end{array}$ \\
\hline Prior hepatitis B treatment & No & No \\
\hline $\begin{array}{l}\text { Clinical evidence of advanced liver } \\
\text { fibrosis }\end{array}$ & Absent & Absent \\
\hline Fibrosis stage & Fibroscan $4.4 \mathrm{KPa}(\mathrm{F} 0)$ & APRI 0.19 (F0-1) \\
\hline Comorbidities & $\begin{array}{l}\text { Hypothyroid, hypertension, latent } \\
\text { tuberculosis infection }\end{array}$ & Gout, psoriasis \\
\hline Medications used & $\begin{array}{l}\text { Levothyroxine, valsartan, isoniazid, } \\
\text { pyridoxine, metformin }\end{array}$ & $\begin{array}{l}\text { Calcipotriol/betamethasone ointment, } \\
\text { Chinese herbal tea }\end{array}$ \\
\hline Diffuse, large B-cell lymphoma stage & Stage IIA & Stage III \\
\hline Lymphoma treatment & R-CHOP x 6 & R-CHOP x 6 \\
\hline Lamivudine start date & 8 days after first chemotherapy & 4 days after first chemotherapy \\
\hline $\begin{array}{l}\text { HBV DNA after } 2 \text { months of LAM } \\
\text { treatment }\end{array}$ & $2.18 \mathrm{E} 1 \mathrm{IU} / \mathrm{mL}$ & $3.96 \mathrm{E} 3 \mathrm{IU} / \mathrm{mL}$ \\
\hline Time of HBV reactivation diagnosis & 18 weeks after R-CHOP number 6 & 7 weeks after R-CHOP number 6 \\
\hline Duration of LAM at HBV reactivation & 7 months & 7 months \\
\hline Lamivudine resistance pattern & L80I, M204I & L80I, M80V, M204V/S \\
\hline HBV status at reactivation & $\begin{array}{l}\text { HBeAg negative, anti-HBe positive, } \\
\text { HBV DNA 1.43E7 IU/mL, ALT } \\
1019 \text { IU/L }\end{array}$ & $\begin{array}{l}\text { HBV DNA 1.02E8 IU/mL, ALT } \\
902 \mathrm{IU} / \mathrm{L}\end{array}$ \\
\hline $\begin{array}{l}\text { Time to death despite tenofovir } \\
\text { treatment }\end{array}$ & 14 days & 3 days \\
\hline
\end{tabular}

${ }^{*}$ HBV DNA at 24 days after starting lamivudine. No baseline HBV DNA was done before lamivudine treatment.

high-level lamivudine resistance, which ultimately led to HBV reactivation, liver failure, and rapid demise.

Although both patients started lamivudine after starting chemotherapy, the short delay in institution of antiviral therapy was unlikely to have affected their outcome. HBV reactivation typically occurs after the third cycle of rituximabbased chemotherapy [3]. The use of prednisone in the first patient was also somewhat atypical; however this was only added after the patient presented with liver failure and had no response to tenofovir. Antiviral therapy does not work immediately, and the liver dysfunction in the acute setting is due primarily to overwhelming hepatic inflammation. Therefore it was felt that the anti-inflammatory effect of prednisone may be helpful, recognizing that with or without steroids the mortality in this setting was likely to be extremely high.

AASLD guidelines recommend that tenofovir or entecavir could be used as an alternative to lamivudine, particularly in patients who are anticipated to require more than 12 months of therapy in whom there is a higher risk of developing lamivudine resistance. $\mathrm{Li}$ et al. compared entecavir and lamivudine in preventing hepatitis $\mathrm{B}$ reactivation in lymphoma patients during chemotherapy and found significantly lower rates of hepatitis (5.9 versus $27.0 \%$,
$P=0.007$ ), hepatitis $\mathrm{B}$ reactivation ( 0 versus $12.4 \%, P=$ 0.024), and disruption of chemotherapy (5.9 versus $20.2 \%$, $P=0.042$ ) in the entecavir-treated patients [14]. There are no specific data comparing tenofovir with other agents in this setting; however its potency, very high barrier to resistance and good safety profile make it a reasonable alternative.

Although only 2 cases, this report highlights that resistance to lamivudine may emerge quickly during immunosuppressive therapy with potentially severe consequences. The use of a more potent agent with a higher barrier to resistance (entecavir or tenofovir) would likely significantly reduce the risk of $\mathrm{HBV}$ reactivation due to antiviral resistance. Arguably had both patients adhered strictly to recommended followup, lamivudine resistance may have been recognized before significant hepatitis occurred, which may have led to improved outcomes. However, particularly during cancer chemotherapy with the many potential unforeseen eventualities, followup with scheduled HBV DNA testing may not be strictly followed. Use of an antiviral agent with a lower risk of resistance would reduce the risk that lapses in scheduled followup and would have significant clinical consequences. A trial to compare the efficacy of different antiviral agents to prevent HBV-reactivation during immunosuppressive therapy is unlikely to be performed, and hence inferences may 
have to be drawn from case reports, case series, and existing data in other clinical settings.

\section{Conclusion}

Lamivudine should not be used for prophylaxis of patients with chronic hepatitis $\mathrm{B}$, especially with detectable $\mathrm{HBV}$ DNA, undergoing chemotherapy with rituximab-based chemotherapy even if lamivudine treatment-naive. In this setting, lamivudine resistance may develop quickly with the risk of severe HBV reactivation and subsequent liver failure that cannot be salvaged with tenofovir. If lamivudine is used initially for chemoprophylaxis, close monitoring of $\mathrm{HBV}$ DNA is required with consideration of a switch to a more potent agent with a higher genetic barrier to resistance if HBV DNA is not suppressed to undetectable levels within 3 months.

\section{References}

[1] S. Kusumoto, Y. Tanaka, R. Ueda, and M. Mizokami, "Reactivation of hepatitis B virus following rituximab-plus-steroid combination chemotherapy," Journal of Gastroenterology, vol. 46, no. 1, pp. 9-16, 2011.

[2] A. M. Evens, B. D. Jovanovic, Y.-C. Su et al., "Rituximabassociated hepatitis B virus (HBV) reactivation in lymphoproliferative diseases: metaanalysis and examination of FDA safety reports," Annals of Oncology, vol. 22, no. 5, pp. 1170-1180, 2011.

[3] U. Zurawska, L. Hicks, G. Woo, C. Bell, M. Krahn et al., "Hepatitis B virus screening before chemotherapy for lymphoma: a cost-effectiveness analysis," Journal of Clinical Oncology, vol. 30, no. 26, pp. 3167-3173, 2012.

[4] C. M. Weinbaum, E. E. Mast, and J. W. Ward, "Recommendations for identification and public health management of persons with chronic hepatitis B virus infection," Hepatology, vol. 49, no. 5, pp. S35-S44, 2009.

[5] L. H. Katz, A. Fraser, A. Gafter-Gvili, L. Leibovici, and R. TurKaspa, "Lamivudine prevents reactivation of hepatitis B and reduces mortality in immunosuppressed patients: systematic review and meta-analysis," Journal of Viral Hepatitis, vol. 15, no. 2, pp. 89-102, 2008.

[6] R. Loomba, A. Rowley, R. Wesley et al., "Systematic review: the effect of preventive lamivudine on hepatitis $\mathrm{B}$ reactivation during chemotherapy," Annals of Internal Medicine, vol. 148, no. 7, pp. 519-528, 2008.

[7] A. S. F. Lok and B. J. McMahon, "Chronic hepatitis B: update 2009," Hepatology, vol. 50, no. 3, pp. 661-662, 2009.

[8] N. Leung, "Clinical experience with lamivudine," Seminars in Liver Disease, vol. 22, no. 1, pp. 15-21, 2002.

[9] F. Von Weizsäcker, "Management of chronic hepatitis B," Praxis, vol. 94, no. 16, pp. 649-652, 2005.

[10] A. M. Pelizzari, M. Motta, E. Cariani, P. Turconi, E. Borlenghi, and G. Rossi, "Frequency of hepatitis B virus mutant in asymptomatic hepatitis B virus carriers receiving prophylactic lamivudine during chemotherapy for hematologic malignancies," Hematology Journal, vol. 5, no. 4, pp. 325-328, 2004.

[11] A.-L. Cheng, C. A. Hsiung, I.-J. Su et al., "Steroid-free chemotherapy decreases risk of hepatitis B virus (HBV) reactivation in HBV-carriers with lymphoma," Hepatology, vol. 37, no. 6, pp. 1320-1328, 2003.
[12] W. Yeo, T. C. Chan, N. W. Y. Leung et al., "Hepatitis B virus reactivation in lymphoma patients with prior resolved hepatitis B undergoing anticancer therapy with or without rituximab," Journal of Clinical Oncology, vol. 27, no. 4, pp. 605-611, 2009.

[13] M. J. Arin, A. Engert, T. Krieg, and N. Hunzelmann, "AntiCD20 monoclonal antibody (rituximab) in the treatment of pemphigus," British Journal of Dermatology, vol. 153, no. 3, pp. 620-625, 2005.

[14] H.-R. Li, J.-J. Huang, H.-Q. Guo et al., "Comparison of entecavir and lamivudine in preventing hepatitis $\mathrm{B}$ reactivation in lymphoma patients during chemotherapy," Journal of Viral Hepatitis, vol. 18, no. 12, pp. 877-883, 2011. 


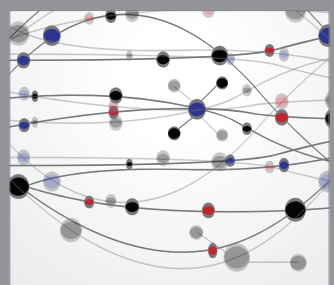

The Scientific World Journal
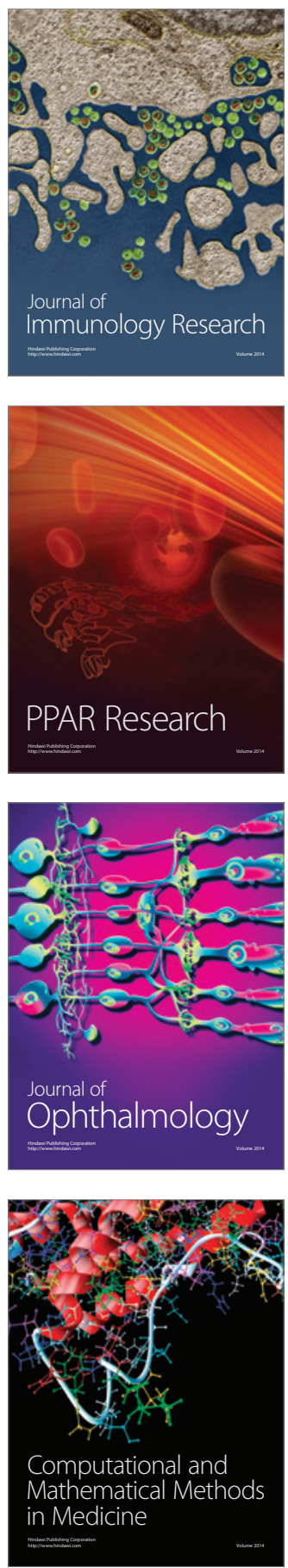

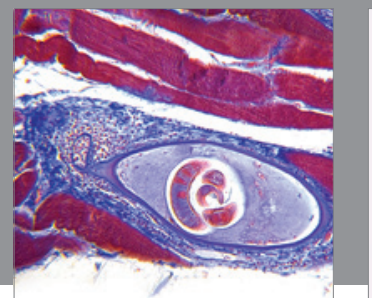

Gastroenterology

Research and Practice
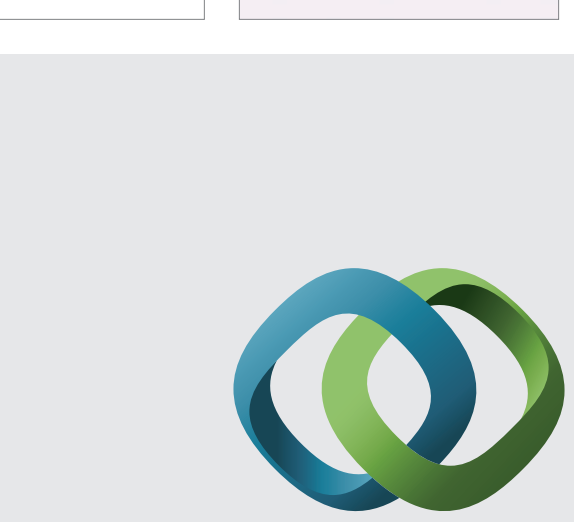

\section{Hindawi}

Submit your manuscripts at

http://www.hindawi.com
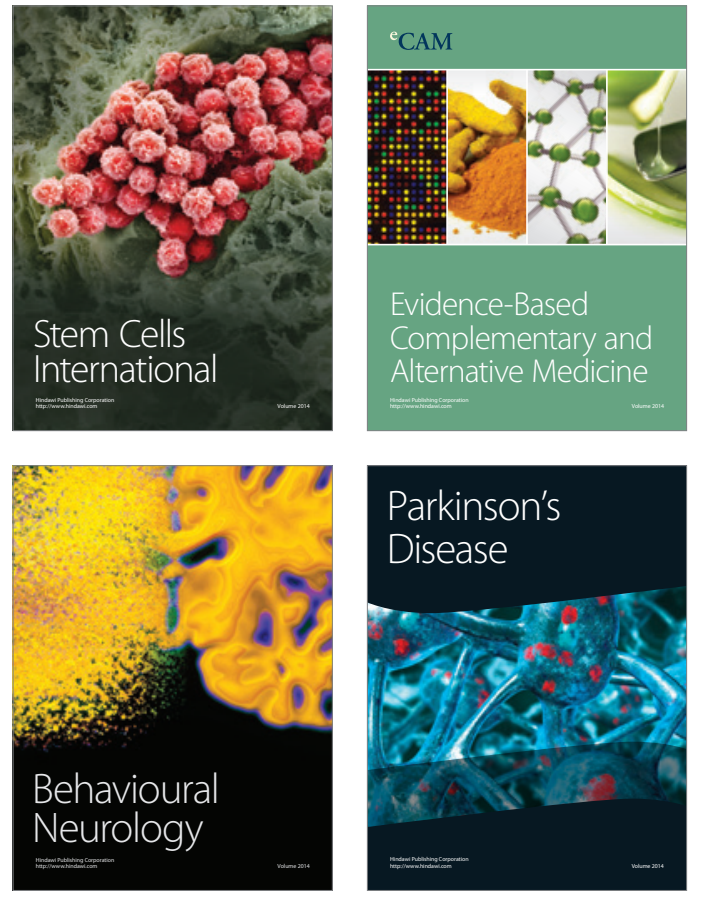
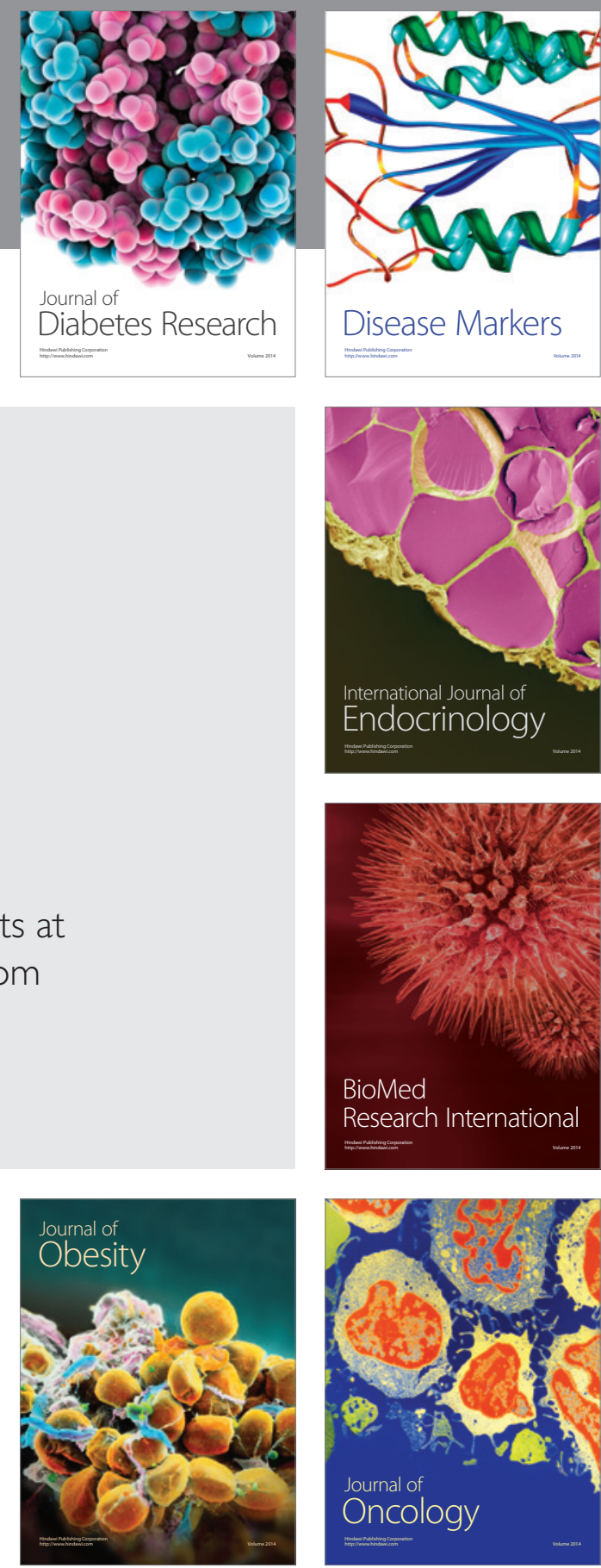

Disease Markers
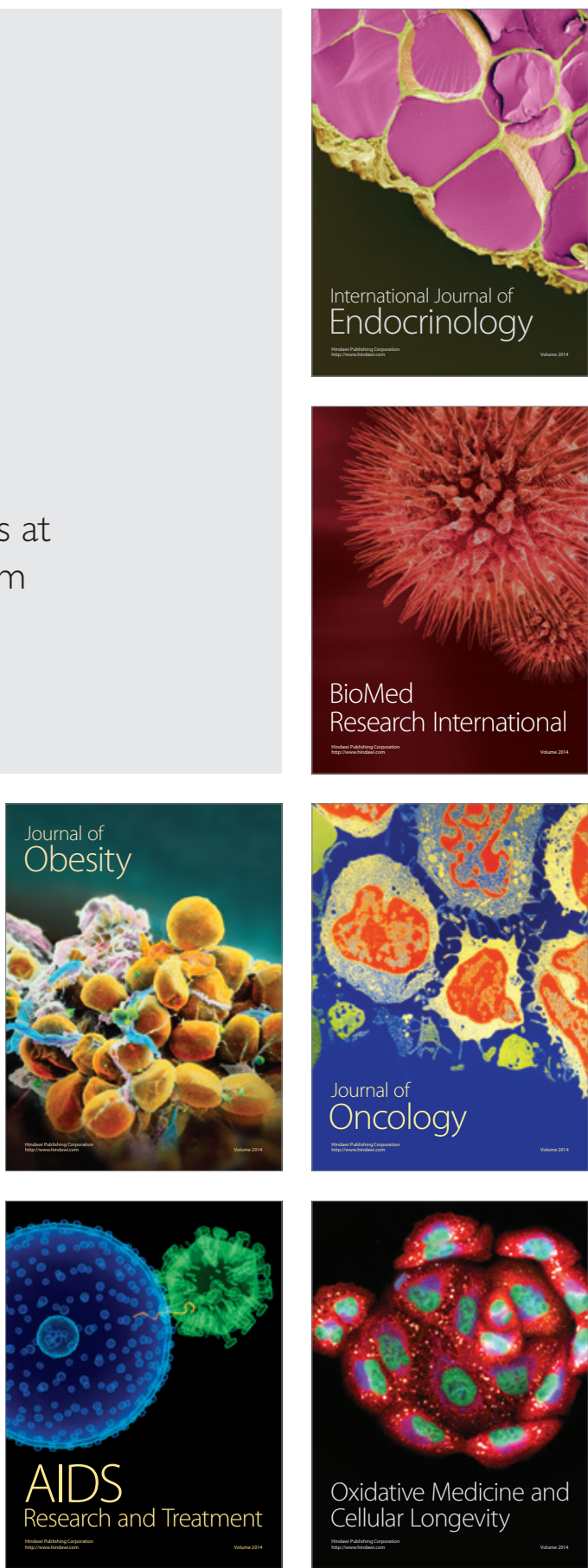